\title{
Oxygen mass transfer in a biphasic medium: Influence on the biotransformation of methyl ricinoleate into $\gamma$-decalactone by the yeast Yarrowia lipolytica
}

\author{
Nelma Gomes, Mario Aguedo, José Teixeira, Isabel Belo* \\ IBB-Institute for Biotechnology and Bioengineering, Centre for Biological Engineering, \\ Universidade do Minho, Campus de Gualtar, 4710-057 Braga, Portugal
}

Received 13 April 2005; received in revised form 30 January 2007; accepted 2 February 2007

\begin{abstract}
In this work, an empirical correlation is proposed to describe $k_{\mathrm{L}} a$ as a function of operating conditions (agitation and aeration rates) and of oil and surfactant volumetric fractions in a biotransformation medium, an oil-in-water dispersion. An interaction effect between the oil and the surfactant effects was found, since oil presence increased $k_{\mathrm{L}} a$ in the absence of the surfactant but had an opposite effect when Tween 80 was available in the medium. The biotransformation of methyl ricinoleate (MR) into $\gamma$-decalactone (an aroma compound of industrial interest), by the yeast Yarrowia lipolytica, was carried out at different conditions of operation, to evaluate the influence of $k_{\mathrm{L}} a$ on the production of the aroma. It was demonstrated that $k_{\mathrm{L}} a$ had an influence on the aroma production; however, for the low hydrophobic substrate concentration used (1.08\% v/v) and cellular density of $2.0 \times 10^{7}$ cells $\mathrm{mL}^{-1}$, a minimal $k_{\mathrm{L}} a$ value of $70 \mathrm{~h}^{-1}$ was necessary to attain the maximal aroma production.
\end{abstract}

(C) 2007 Elsevier B.V. All rights reserved.

Keywords: Oxygen transfer; $k_{\mathrm{L}} a$; Biphasic medium; Yarrowia lipolytica; $\gamma$-Decalactone

\section{Introduction}

In microbial cultivation processes, particularly on high-celldensity cultures, productivity is often limited by the transport of a substrate, of which oxygen is one example. Oxygen transfer rate (OTR) depends on the fluid physical properties, temperature, pressure, solution composition, agitation, oxygen superficial gas velocity and the configuration of the reactor [1]. OTR in a system is a function of the volumetric mass transfer coefficient, $k_{\mathrm{L}} a$, and the oxygen solubility in the medium. For a specific bioreactor and medium, it is possible to increase $k_{\mathrm{L}} a$ and, consequently, OTR, using high agitation and aeration rates. However, this causes high power consumption, significantly increasing operation costs. High stirring rates also present a limitation when applied to cells sensitive to hydrodynamic stress. The addition of a second, water-immiscible phase, in which oxygen has a higher solubility, has been proposed by several authors as an alternative mean of OTR improvement. Most of the experiments described in the literature were carried out using a hydrocarbon

\footnotetext{
* Corresponding author. Tel.: +351 253604 413; fax: +351 253678986 .

E-mail address: ibelo@deb.uminho.pt (I. Belo).
}

or a perfluorocarbon (PFC) as an inert dispersed phase in the aqueous medium. The effects of adding a second liquid organic phase on $k_{\mathrm{L}} a$ may change, and it was shown that $k_{\mathrm{L}} a$ values may increase, decrease, or remain constant, depending on the nature of the organic compound and the operating conditions [2-14].

In order to take into account the effect of the organic phase on $k_{\mathrm{L}} a$, empirical correlations (Eq. (1)) have been proposed, assuming that the two liquid phases behave as a single homogeneous phase [15].

$k_{\mathrm{L}} a=\delta\left(\frac{P_{\mathrm{g}}}{V}\right)^{\alpha}\left(v_{\mathrm{s}}\right)^{\beta}\left(1-X_{\mathrm{ORG}}\right)^{\gamma}$

where $P_{g}$ represents the power input of the aerated bioreactor, $V$ the bioreactor working volume, $v_{\mathrm{s}}$ the superficial gas velocity through the bioreactor, $X_{\mathrm{ORG}}$ the fraction of the total bioreactor working volume that is in the organic phase, and $\delta, \alpha, \beta$ and $\gamma$ are numerical constants.

Prediction of $k_{\mathrm{L}} a$ in oil-in-water emulsions is of great importance due to the numerous biotechnological processes based on the development of microorganisms within a biphasic media.

One example of a gas-liquid-liquid system is the medium used in the biotransformation of methyl ricinoleate (MR) 


\begin{tabular}{|c|c|}
\hline \multicolumn{2}{|c|}{ Nomenclature } \\
\hline$a$ & specific interfacial area $\left(\mathrm{m}^{-1}\right)$ \\
\hline$c$ & constant, dependent on the impeller used \\
\hline$D_{\mathrm{i}}$ & impeller diameter $(\mathrm{cm})$ \\
\hline$D_{\mathrm{t}}$ & bioreactor vessel diameter $(\mathrm{cm})$ \\
\hline$F_{\mathrm{g}}$ & volumetric gas flow $\left(\mathrm{m}^{3} \mathrm{~s}^{-1}\right)$ \\
\hline$h_{\mathrm{i}}$ & impeller height rate $(\mathrm{cm})$ \\
\hline$h_{\mathrm{t}}$ & bioreactor vessel height $(\mathrm{cm})$ \\
\hline$k_{\mathrm{L}}$ & liquid side mass transfer coefficient $\left(\mathrm{m} \mathrm{s}^{-1}\right)$ \\
\hline$k_{\mathrm{L}} a$ & oxygen volumetric mass transfer coefficient $\left(\mathrm{h}^{-1}\right)$ \\
\hline$K_{\mathrm{T}}$ & constant dependent on the impeller used \\
\hline$N$ & agitation rate (rps) \\
\hline$N_{\mathrm{p}}$ & power number \\
\hline$N_{\mathrm{Re}}$ & Reynolds number \\
\hline OD & optical density \\
\hline OTR & oxygen transfer rate $\left(\mathrm{g} \mathrm{L}^{-1} \mathrm{~h}^{-1}\right)$ \\
\hline$P_{\mathrm{g}}$ & power input to the aerated system (W) \\
\hline$P_{\mathrm{g}}^{\prime}$ & power input to the non-aerated system (W) \\
\hline $\mathrm{rpm}$ & rotations per minute \\
\hline$t$ & time $(\mathrm{h})$ \\
\hline$V$ & volume $\left(\mathrm{m}^{3}\right)$ \\
\hline & superficial gas velocity $\left(\mathrm{m} \mathrm{s}^{-1}\right)$ \\
\hline$X_{\mathrm{ORG}}$ & organic fraction $\left(\mathrm{LL}^{-1}\right)$ \\
\hline$X_{\mathrm{MR}}$ & MR fraction $\left(\mathrm{L} \mathrm{L}^{-1}\right)$ \\
\hline$X_{\text {Tween }}$ & Tween fraction $\left(\mathrm{LL}^{-1}\right)$ \\
\hline \multicolumn{2}{|c|}{ Greek letters } \\
\hline \multicolumn{2}{|c|}{$\alpha, \beta, \delta, \gamma, \phi$ nonlinear model parameters to be fitted } \\
\hline$\rho$ & density $\left(\mathrm{kg} \mathrm{m}^{3}\right)$ \\
\hline$v$ & viscosity $\left(\mathrm{kg} \mathrm{m}^{-1} \mathrm{~s}^{-1}\right)$ \\
\hline$\tau$ & probe time response $\left(\mathrm{s}^{-1}\right)$ \\
\hline
\end{tabular}

into $\gamma$-decalactone, a fruity and creamy aroma compound, where the organic phase is the substrate used by the cells and not an inert compound used with the only purpose of increasing OTR. The biotransformation can be carried out by the yeast Yarrowia lipolytica that is strictly aerobic and one of the most studied "non-conventional" yeast species. Beyond its interest for fundamental research due to many specificities, this yeast is also interesting for biotechnological applications, since it is able to produce several metabolites in large amounts (i.e. organic acids, extracellular proteins, etc.) $[16,17] . \quad Y$. lipolytica is able to transform MR into $\gamma$-decalactone, resulting from the peroxisomal $\beta$-oxidation of ricinoleic acid [18,19]. Oxygen is an intervening factor in the metabolic pathway involved in this biotransformation, participating in the reactions of production and re-consumption of the aroma. Therefore, evaluation of the impact of biphasic medium oxygenation has a great interest in order to optimise the bioprocess.

The aim of this work is to investigate the effect of $k_{\mathrm{L}} a$ on the production of $\gamma$-decalactone from MR. Firstly, an analysis of the effects of operating conditions (agitation and aeration rates), in a stirred tank fermenter, and the medium composition (organic and surfactant volumetric fractions) on $k_{\mathrm{L}} a$ was performed and described by an empirical correlation. Lately, based on the predicted $k_{\mathrm{L}} a$ values, the $k_{\mathrm{L}} a$ effect on the production of $\gamma$-decalactone was studied.

\section{Experimental techniques}

\subsection{Oxygen mass transfer}

\subsubsection{Bioreactor}

A total working volume of $1.7 \mathrm{~L}$ was used in a $2 \mathrm{~L}$ bioreactor (Biolab, B. BRAUN; $h_{\mathrm{t}}=21 \mathrm{~cm}, D_{\mathrm{t}}=11 \mathrm{~cm}$ ). The two-phase liquid dispersion was agitated with two six-blade turbine impellers $\left(h_{\mathrm{i}}=1.5 \mathrm{~cm}, D_{\mathrm{i}}=5.7 \mathrm{~cm}\right)$. Agitation rates of $300,400,500$ and $600 \mathrm{rpm}$ were used, and the aeration rates were $0.3,0.6$ and 0.9 vvm. Air was supplied to the bioreactor with a sparger located at the base of the agitator shaft.

\subsubsection{Media composition}

The organic phase consisted of $10 \mathrm{~g} \mathrm{~L}^{-1}(1.08 \% \mathrm{v} / \mathrm{v}) \mathrm{MR}$ (Stéarinerie Dubois, Boulogne, France). The aqueous phase of the medium was composed of $2.5 \mathrm{~g} \mathrm{~L}^{-1} \mathrm{NH}_{4} \mathrm{Cl}, 6.7 \mathrm{~g} \mathrm{~L}^{-1}$ yeast nitrogen base (YNB) and $0.1 \mathrm{M}$ phosphate buffer $(\mathrm{pH}=7)$. One gram per liter $(0.093 \% \mathrm{v} / \mathrm{v})$ Tween 80 was used as surfactant. For $k_{\mathrm{L}} a$ studies, MR volumetric fractions of 0 , $0.27,0.54$ and $1.08 \%$ and Tween 80 volumetric fractions of $0,0.023,0.047$ and $0.093 \%$ were used. In the biotransformation experiments, the maximum concentration of MR and Tween 80 was used, since these were conditions previously found as optimum for the aroma production in shake flasks [19].

\subsubsection{Experimental procedure}

For the experimental $k_{\mathrm{L}} a$ determination, the static gassingout technique was used [20]. Dissolved oxygen concentration was measured with a polarographic-membrane probe $(12 / 220 \mathrm{~T}$, Mettler Toledo) and monitored with a computer interface (CIODAS08JR, Computer Boards, EUA) at $5 \mathrm{~s}$ intervals using the software LABtech Notebook, Datalab Solution. To estimate the probe response time $(\tau)$, it was used the method that describes the response of the probe to a step in dissolved oxygen concentration by a first-order system [20]. The obtained $\tau$ value of $7 \mathrm{~s}$ at $27^{\circ} \mathrm{C}$ was used to correct $k_{\mathrm{L}} a$ values.

Between runs, the bioreactor was de-aerated by sparging with compressed $\mathrm{N}_{2}$ until only minimum levels of dissolved oxygen remain $(\approx 0 \%$ saturation). At this point, air was diffused into the bioreactor until saturation and dissolved oxygen concentration was monitored through time, as shown in Fig. 1. All experiments were carried out at $27^{\circ} \mathrm{C}$, and at each medium composition, measurements of $k_{\mathrm{L}} a$ were performed at all stirring and aeration rates mentioned above.

\subsubsection{Modelling}

Data fitting to empirical equations based on Eq. (1) were performed by least-squares non-linear regression using the Solver tool of Microsoft Excel 2003 software. 


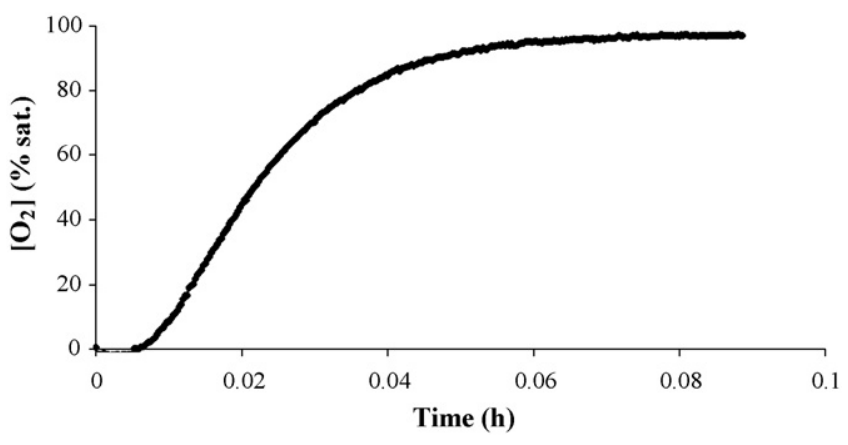

Fig. 1. Time course of dissolved oxygen concentration during $k_{\mathrm{L}} a$ determination by gassing-out method at $400 \mathrm{rpm}$ and $0.6 \mathrm{vvm}$.

\subsection{Biotransformation}

\subsubsection{Strains, media and culture conditions}

Y. lipolytica W29 (ATCC20460; CLIB89) was cultured for $48 \mathrm{~h}$ on malt extract agar $\left(50 \mathrm{~g} \mathrm{~L}^{-1}\right)$ at $27^{\circ} \mathrm{C}$ and used to inoculate (to an optical density at $600 \mathrm{~nm}\left(\mathrm{OD}_{600}\right)$ of 0.25 ) a $500 \mathrm{~mL}$ Erlenmeyer flask containing $200 \mathrm{~mL}$ of a pH 5.6 glucose medium containing per litre: $15 \mathrm{~g} \mathrm{~L}^{-1}$ glucose, $2.5 \mathrm{~g} \mathrm{~L}^{-1}$ $\mathrm{NH}_{4} \mathrm{Cl}, 2.1 \mathrm{gL}^{-1} \quad \mathrm{KH}_{2} \mathrm{PO}_{4}, \quad 3.6 \mathrm{gL}^{-1} \quad \mathrm{Na}_{2} \mathrm{HPO}_{4}, 0.2 \mathrm{gL}^{-1}$ $\mathrm{MgSO}_{4} \cdot 7 \mathrm{H}_{2} \mathrm{O}, 0.1 \mathrm{~g} \mathrm{~L}^{-1} \mathrm{NaCl}, 0.005 \mathrm{~g} \mathrm{~L}^{-1} \mathrm{FeSO}_{4}, 0.001 \mathrm{gL}^{-1}$ $\mathrm{CuSO}_{4}, 5 \times 10^{-4} \mathrm{~g} \mathrm{~L}^{-1} \quad \mathrm{ZnCl}_{2}$ and $0.1 \mathrm{gL}^{-1}$ yeast extract. Flasks were shaken at $140 \mathrm{rpm}$ and $27^{\circ} \mathrm{C}$ for $19 \mathrm{~h}$ until the cultures reached the late logarithmic growth phase. Cells were then washed $(6000 \times g, 5 \mathrm{~min})$ three times in sterile water and transferred to the biotransformation medium at $\mathrm{OD}_{600}$ of 1.2, containing a MR fraction of $1.08 \%(\mathrm{v} / \mathrm{v})$ and a Tween 80 fraction of $0.093 \%(\mathrm{v} / \mathrm{v})$.

In order to study the effect of $k_{\mathrm{L}} a$ values on the production of $\gamma$-decalactone, several experiments were carried out by changing agitation and aeration rates, keeping the oil fraction unchanged (initial concentration of $1.08 \%$ ), as well as the Tween 80 volumetric fraction $(0.093 \%)$. $k_{\mathrm{L}} a$ was assessed during the biotransformation by the dynamic method. Aeration was stopped until dissolved oxygen concentration decreased to a minimum level of 1.5 -fold the critical value (15\% saturation), followed by re-aeration.

\subsubsection{Extraction and analyses}

For the quantification of $\gamma$-decalactone, $2 \mathrm{~mL}$ medium samples were removed and extracted with $2 \mathrm{~mL}$ diethyl ether by 10 gentle shakings after addition of $\gamma$-undecalactone as inter- nal standard. After $2 \mathrm{~min}$, the ether phase was analysed by gas chromatography (CP 9001, CHROMPACK) with a TRWAX capillary column $(30 \mathrm{~m} \times 0.32 \mathrm{~mm} \times 0.25 \mu \mathrm{m})$ with He as a carrier gas. The temperatures of the split injector and the detector were set to 250 and $300^{\circ} \mathrm{C}$, respectively. The oven temperature was programmed to increase from 60 to $145^{\circ} \mathrm{C}$ at a rate of $5^{\circ} \mathrm{C} \mathrm{min}^{-1}$ and then to $180^{\circ} \mathrm{C}$ at a rate of $2^{\circ} \mathrm{C} \mathrm{min}^{-1}$.

\section{Results and discussion}

\subsection{Effect of the biphasic medium on $k_{L}$ a values}

To evaluate the effect of biotransformation medium (biphasic) on $k_{\mathrm{L}} a$ values, several experiments were carried out, changing agitation and aeration rates, as well as its composition in oil (MR) and surfactant (Tween 80).

The effects of agitation and aeration rates on $k_{\mathrm{L}} a$ were measured in the aqueous media without any organic fraction (Fig. 2A). This set of experiments was used as a control and was repeated adding to the medium different concentrations of oil (volumetric fractions of $0,0.27,0.54$ and $1.08 \%$ ) and surfactant (volumetric fractions of $0,0.023,0.047$ and $0.093 \%$ ). In Fig. 2B-D, some examples of the determinations performed in the medium without cells are presented.

Data were fitted to empirical correlations based on Eq. (1), to predict $k_{\mathrm{L}} a$ values as a function of operating conditions and organic and surfactant phase content (Table 1).

To calculate the power input to the aerated system $\left(P_{g}\right)$, Reynolds number $\left(N_{\mathrm{Re}}\right)$ was determined by Eq. (6) and power number $\left(N_{\mathrm{p}}\right)$ by Eq. (7).

$$
\begin{aligned}
& N_{\mathrm{Re}}=\frac{D_{i}^{2} \times N \times \rho}{v} \\
& N_{\mathrm{p}}=\frac{P_{\mathrm{g}}}{\rho \times N^{3} \times D_{\mathrm{i}}^{5}}
\end{aligned}
$$

where $\rho$ represents the liquid density, $N$ the agitation rate and $D_{\mathrm{i}}$ the impeller diameter.

According to Cheremisinoff and Gupta [21], since the flow of the system is turbulent $\left(19070<N_{\mathrm{Re}}<38141\right), N_{\mathrm{p}}$ is not a function of $N_{\mathrm{Re}}$ when the vessel is fully baffled. Consequently, $P_{\mathrm{g}}$ without aeration $\left(P_{\mathrm{g}}^{\prime}\right)$ can be determined by Eq. (8).

$$
P_{\mathrm{g}}^{\prime}=K_{\mathrm{T}} \times D_{\mathrm{i}}^{5} \times N^{3} \times \rho
$$

Table 1

Correlations obtained for different operating conditions (agitation and aeration rates) and media compositions (organic and surfactant fractions)

\begin{tabular}{lll}
\hline Volumetric organic fraction $(\%)$ & Volumetric surfactant fraction $(\%)$ & Equations \\
\hline 0 & 0 & $k_{\mathrm{L}} a=1245\left(\frac{P_{\mathrm{g}}}{V}\right)^{0.4}\left(v_{\mathrm{s}}\right)^{0.8}$ \\
$0,0.27,0.54,1.08$ & 0 & $k_{\mathrm{L}} a=371\left(\frac{P_{\mathrm{g}}}{V}\right)^{0.6}\left(v_{\mathrm{S}}\right)^{0.8}\left(1-X_{\mathrm{RM}}\right)^{-22}$ \\
0 & $0,0.023,0.047,0.093$ & $k_{\mathrm{L}} a=469\left(\frac{P_{\mathrm{g}}}{V}\right)^{0.4}\left(v_{\mathrm{s}}\right)^{0.7}\left(1-X_{\text {Tween }}\right)^{-449}$ \\
$0,0.27,0.54,1.08$ & $0,0.023,0.047,0.093$ & $k_{\mathrm{L}} a=243\left(\frac{P_{\mathrm{g}}}{V}\right)^{0.6}\left(v_{\mathrm{s}}\right)^{0.6}\left(1-X_{\mathrm{RM}}\right)^{3}\left(1-X_{\mathrm{Tween}}\right)^{-141} \quad(5)$ \\
\hline
\end{tabular}



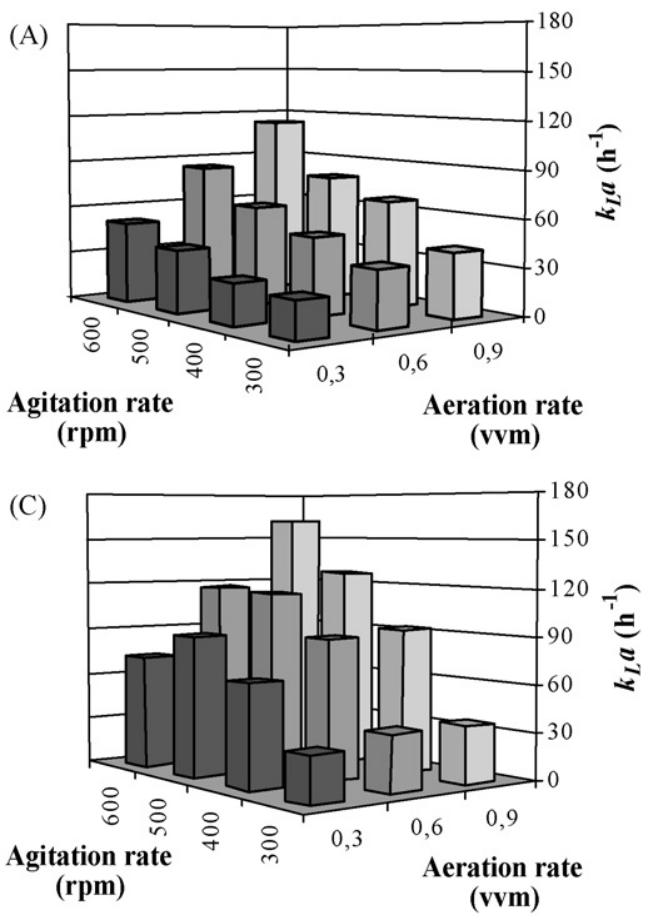
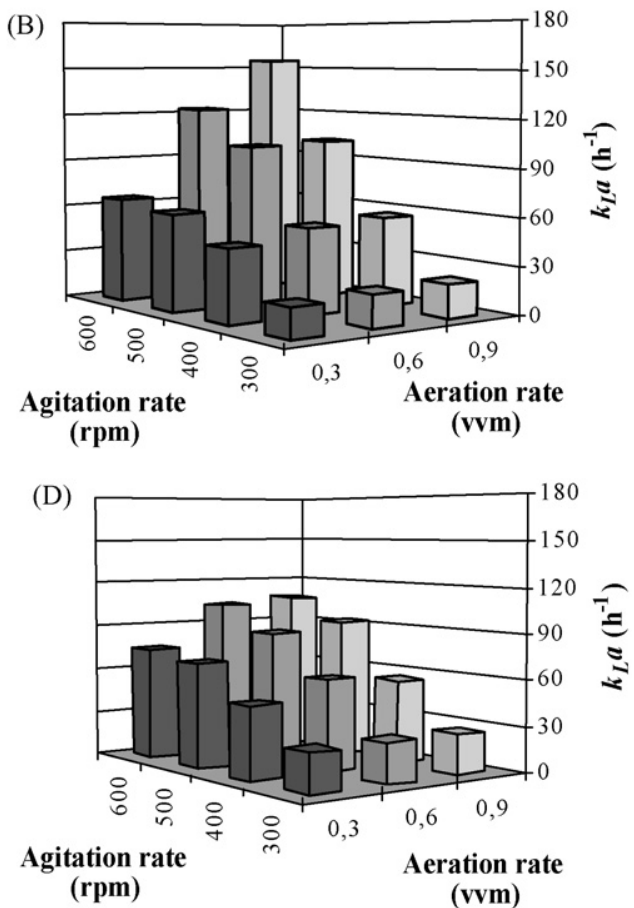

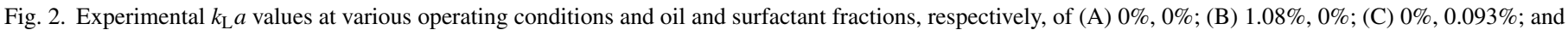
(D) $1.08 \%, 0.093 \%$.

where $K_{\mathrm{T}}$ (equal to 6.3 ) is a constant dependent on the impeller used.

Finally, to determine $P_{\mathrm{g}}$ in an aerated system, Eq. (9) was used.

$P_{\mathrm{g}}=c \times\left(\frac{P_{\mathrm{g}}^{\prime} \times N \times D_{\mathrm{i}}^{3}}{F_{\mathrm{g}}^{0.56}}\right)^{0.45}$

where $c$ (equal to 0.15 ) is a constant dependent on the impeller used and $F_{\mathrm{g}}$ is the volumetric gas flow rate.

Numerical values of $P_{\mathrm{g}}$ and $v_{\mathrm{s}}$ are listed in Table 2 .

According to Eq. (2), it can be seen that results obtained in the present work in a medium without oil and surfactant show that $k_{\mathrm{L}} a$ dependence is higher on aeration rate than on agitation rate. Moo-Young and Blanch [22] suggested values of 0.7 and 0.3 for the parameters $\alpha$ and $\beta$, respectively, for non-coalescent media and of 0.4 and 0.5 , respectively, for coalescent media, for a stirred reactor with a six flat-bladed disk turbine. Thus, this indicates that the medium used in this work, without oil or surfactant fractions, has a coalescent behaviour.

Table 2

Power input $\left(P_{\mathrm{g}}\right)$ and gas superficial velocity $\left(v_{\mathrm{s}}\right)$ for operating conditions used for the determination of $k_{\mathrm{L}} a$ correlations

\begin{tabular}{llllll}
\hline $\begin{array}{l}\text { Aeration rate } \\
(\text { vvm })\end{array}$ & $v_{\mathrm{s}}\left(\mathrm{m} \mathrm{s}^{-1}\right)$ & $P_{\mathrm{g}}(\mathrm{W})$ & & & \\
\cline { 3 - 6 } & & $300 \mathrm{rpm}^{\mathrm{a}}$ & $400 \mathrm{rpm}^{\mathrm{a}}$ & $500 \mathrm{rpm}^{\mathrm{a}}$ & $600 \mathrm{rpm}^{\mathrm{a}}$ \\
\hline 0.3 & $8.77 \times 10^{-4}$ & 0.064 & 0.157 & 0.317 & 0.564 \\
0.6 & $1.75 \times 10^{-3}$ & 0.053 & 0.132 & 0.267 & 0.473 \\
0.9 & $2.63 \times 10^{-3}$ & 0.048 & 0.119 & 0.241 & 0.427 \\
\hline
\end{tabular}

\footnotetext{
a Agitation rate
}

In two-liquid phase systems, in which the organic phase is dispersed in the aqueous phase, the effect of the organic compound on $k_{\mathrm{L}} a$ can be taken into account by Eq. (1), assuming the equilibrium of dissolved oxygen between the aqueous continuous phase and the organic dispersed phase. This assumption is valid since, at all agitation rates, Reynolds numbers suggest that the system is in the turbulent flow regime. Eq. (3) shows the result obtained by fitting data with organic phase concentrations of $0,0.54$ and $1.08 \%$ ( $X_{\mathrm{ORG}}$ equal to $0,0.0054$ and 0.0108 ) in the absence of surfactant (data from Fig. $2 \mathrm{~A}$ and B and equivalent data to $0.54 \%$, not shown).

From Eq. (3), it can be seen that the presence of the organic fraction in the absence of surfactant improves $k_{\mathrm{L}} a$, particularly at high stirring rates. This effect has been attributed to the decrease of bubble diameter and consequently gas hold-up increase due to the oil addition [23], which consequently increases the interfacial area for the gas-liquid mass transfer. Previous work [9] suggests that interfacial properties of the organic phase have more influence in the behaviour of gas-liquid-liquid systems than the hydrodynamic effects, since $P_{\mathrm{g}}$ can be assumed independent of oil fraction. Addition of MR in the system also led to an increase in the $k_{\mathrm{L}} a$ dependence on agitation. This is in accordance with the fact that agitation rate is a very important factor to increase the organic phase dispersion in the aqueous phase, improving gas-liquid mass transfer [24].

The enhancement of oxygen mass transfer in fermentations containing an immiscible liquid phase is an effect previously reported by other authors for different systems [2-14]. However, using the empirical correlation represented by Eq. (1), values of $650,0.3,0.7$ and 1.7 were obtained by Nielsen et al. [15] for 
the parameters $\delta, \alpha, \beta$ and $\gamma$, respectively, which means that for the system referred, $k_{\mathrm{L}} a$ values were also more dependent on aeration than on agitation, but the presence of the organic phase decreased $k_{\mathrm{L}} a$ values. This difference can be justified by the use of different organic phases in both works: while oil is MR in this work, $n$-hexadecane was used in the mentioned work. Another difference that should be taken into account is the organic phase content tested. In this work, very small fractions were tested: 0, 0.27, 0.54 and $1.08 \%$, while Nielsen et al. [15] used organic fraction values up to $33 \%$.

In order to analyse the surfactant influence on $k_{\mathrm{L}} a$ values, in the absence of the immiscible organic phase, Eq. (1) was fitted to data obtained with medium without oil and with surfactant volumetric fractions from 0 to $0.093 \%$ (data from Fig. 2A-C and equivalent data for $0.023 \%$ and $0.047 \%$ of surfactant, figures not shown). In Eq. (1), $X_{\text {ORG }}$ was replaced by $X_{\text {Tween }}$, which is the volumetric fraction of Tween 80 in the total bioreactor working volume. The magnitude of the $\gamma$ parameter obtained in this case (Eq. (4)) indicates that small amounts of Tween 80 strongly increase $k_{\mathrm{L}} a$ values. The effect of surfactants on oxygen mass transfer in aqueous systems with a single liquid phase has been usually reported as negative [25-28], as a result of the balance in the two competitive effects of surfactants: the increase in the resistance to oxygen transfer $\left(k_{\mathrm{L}}\right.$ decrease) and the increase in the specific interfacial area $(a)$ [28].

For the conditions used in the present work, the influence of Tween 80 in the decrease of air bubble size was probably more significant than the influence on the interfacial properties (e.g. rigidity).

Based on Eq. (1), a generalized correlation is proposed, taking into account the presence of both fractions in the medium (organic and surfactant); however, discriminating their effects (Eq. (5)).

This correlation was obtained by fitting the model to all experimental data with different organic and surfactant fractions $(0$, 0.54 and $1.08 \%$ of MR and $0 \%, 0.023,0.047$ and $0.093 \%$ of Tween 80 ) and at all the aeration and stirring rates used. In Fig. 3, predicted versus experimental results are shown with a line slope close to 1 , which indicates a good approximation between real $k_{\mathrm{L}} a$ values and the values calculated by the correlation.

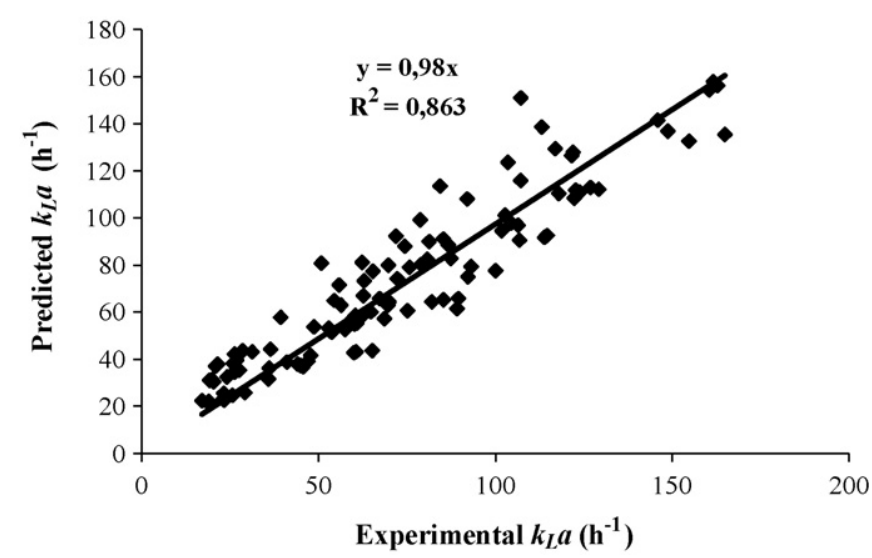

Fig. 3. Predicted versus experimental $k_{\mathrm{L}} a$ values using Eq. (3) with estimated parameters.
The relation between the $k_{\mathrm{L}} a$ values predicted by the correlations and the experimental values presents a dispersion commonly found in this type of fitting [15], which is reflected in the low value of the correlation coefficient, $R^{2}$.

For the highest fractions of Tween 80 and MR tested, which correspond to the biotransformation medium composition usually used [29], $k_{\mathrm{L}} a$ values are smaller than those observed with smaller fractions, as it can be seen in Fig. 2A and D. In fact, there is an interaction of MR and Tween 80 effects, since, according to Eq. (5), the increase in the MR fraction has a negative effect on $k_{\mathrm{L}} a$, which is opposite to the effect observed without surfactant in the medium. This fact can be attributed to the high impact of surfactant on the air/aqueous phase interface, since there is still surfactant in the aqueous phase, which is the largest phase in the system, in spite of the fact that most of the surfactant is at the oil surface. The positive effect of oil can be overcome by the surfactant effect. Nevertheless, as stressed by Nielsen et al. [15], even when oil presence in the medium has a negative impact on $k_{\mathrm{L}} a$, the global effect on OTR is generally positive due to the increase in the driving force for mass transfer, by high oxygen affinity hydrophobic compounds, such as MR.

\subsection{Production of $\gamma$-decalactone}

The correlation obtained enables the prediction of $k_{\mathrm{L}} a$ as a function of operating conditions. In order to analyse the effect of $k_{\mathrm{L}} a$ on $\gamma$-decalactone production, only aeration and stirring rates were manipulated to obtain different values of the coefficient. Since the change of MR and Tween 80 will also interfere with the biological reaction and results would be difficult to analyse, the volumetric fractions of these compounds were kept constant in the biotransformation process.

After the growth phase, cells were transferred to the biotransformation medium to produce $\gamma$-decalactone through MR biotransformation.

In Fig. 4, the time course of dissolved oxygen concentration in the biotransformation medium and $\gamma$-decalactone production at two different operating conditions is presented.

It is possible to see in Fig. 4 that, using low agitation and aeration rates, a complete depletion of dissolved oxygen occurred in the medium. On the contrary, using high agitation and aeration rates, dissolved oxygen concentration was above $70 \%$ of saturation during the whole experiment.

It can be observed that the maximal $\gamma$-decalactone production is obtained at $10 \mathrm{~h}$, and after this time, its concentration decreases until complete disappearance due to its degradation by the yeast.

Comparing the maximal production of $\gamma$-decalactone in both cases presented, 78 and $110 \mathrm{mg} \mathrm{L}^{-1}$ for experiments $\mathrm{A}$ and $\mathrm{B}$, respectively, it seems that operating conditions responsible for higher $k_{\mathrm{L}} a$ values enhance $\gamma$-decalactone production.

\subsection{Effect of $k_{L}$ a values in the production of $\gamma$-decalactone}

The influence of $k_{\mathrm{L}} a$ on the production of $\gamma$-decalactone was studied in biotransformations with different operating 

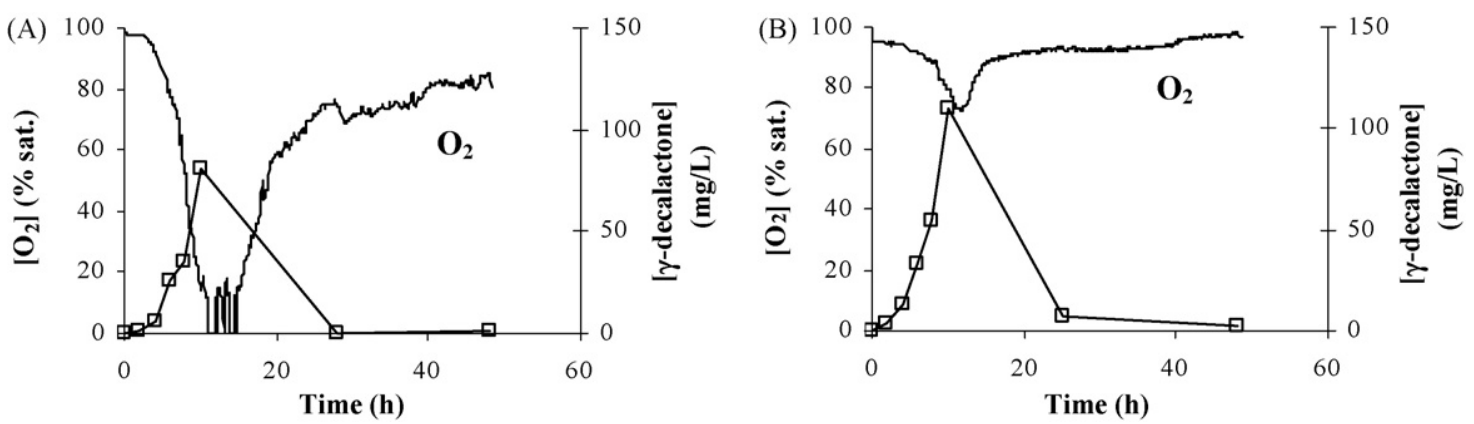

Fig. 4. Time course of dissolved oxygen concentration and $\gamma$-decalactone ( $\square$ ) production at different agitation and aeration rates: (A) $300 \mathrm{rpm}$ and $0.3 \mathrm{vvm}$, and (B) $600 \mathrm{rpm}$ and $0.9 \mathrm{vvm}$

Table 3

$k_{\mathrm{L}} a$ values at different operating conditions

\begin{tabular}{|c|c|c|c|c|c|c|c|}
\hline & \multicolumn{7}{|c|}{ Experiment } \\
\hline & 1 & 2 & 3 & 4 & 5 & 6 & 7 \\
\hline Agitation rate (rpm) & 300 & 300 & 400 & 400 & 600 & 600 & 600 \\
\hline$k_{\mathrm{L}} a$ without cells $\left(\mathrm{h}^{-1}\right)^{\mathrm{a}}$ & 26 & 34 & 41 & 54 & 104 & 123 & 162 \\
\hline$k_{\mathrm{L}} a$ with cells $\left(\mathrm{h}^{-1}\right)^{\mathrm{b}}$ & $26 \pm 2.6$ & $32 \pm 3.2$ & $49 \pm 4.9$ & $70 \pm 7$ & $102 \pm 10.2$ & $125 \pm 12.5$ & $151 \pm 15.1$ \\
\hline
\end{tabular}

${ }^{a}$ Predicted by correlation of Eq. (5).

${ }^{b}$ Data are average values $\pm 95 \%$ confidence interval.

conditions (Table 3) selected according to the established $k_{\mathrm{L}} a$ correlation. $k_{\mathrm{L}} a$ in the biotransformation process was determined at $9 \mathrm{~h}$, close to the time at which the maximum production of $\gamma$-decalactone is generally obtained.

The presence of cells (average concentration of $2.0 \times 10^{7}$ cells mL ${ }^{-1}$ ) in the medium did not significantly affect $k_{\mathrm{L}} a$, probably due to the low cell density used or maybe there was a balance between the possible negative effects of cells as particle solids [30] and the possible positive effects due to oxygen consumption by the cells accumulated at the gas-liquid interface [31].

The maximum production of $\gamma$-decalactone obtained for biotransformations under different operating conditions is shown in Fig. 5.

Productions of $\gamma$-decalactone were weaker than the values previously reported [19] using $500 \mathrm{~mL}$ baffled flasks containing $200 \mathrm{~mL}$ of biotransformation medium, under an agitation

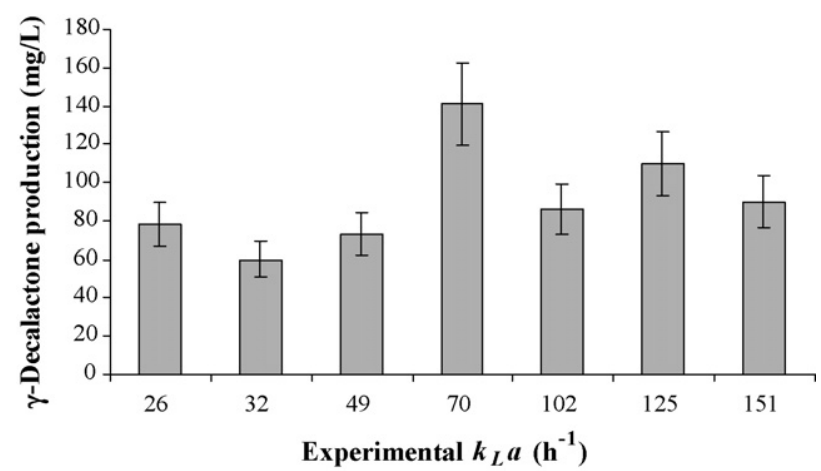

Fig. 5. Production of $\gamma$-decalactone under different $k_{\mathrm{L}} a$ values. Bars are $95 \%$ confidence interval. rate of $140 \mathrm{rpm}$. For those conditions, productions between 250 and $300 \mathrm{mg} \mathrm{L}^{-1}$ were achieved with a cell density of $1.0 \times 10^{8}$ cells $\mathrm{mL}^{-1}$. This difference may be justified by the use of different cell concentrations of the inoculum, which shows that cell concentration is also an important factor in the process. However, the specific production of aroma was two-fold higher in the bioreactor than in the flasks.

Results (Fig. 5) show that the production of $\gamma$-decalactone is affected by $k_{\mathrm{L}} a$ (variance analysis, $P=0.05$ ). Moreover, it seems that a minimum value of $k_{\mathrm{L}} a$ of $70 \mathrm{~h}^{-1}$ is required to attain the maximum production at the operating conditions used. This value is in-between the all range of $k_{\mathrm{L}} a$ values tested in the experiments and seems to be sufficient for a maximal $\gamma$-decalactone production, based on the existing biomass and the amount of substrate to degrade. Besides the oxygen transfer effects, by using lower agitation rates, the production process can be less efficient, probably due to the achievement of an emulsion with a smaller interfacial surface (composed of bigger droplets). On the other hand, the use of higher agitation rates may cause metabolic alterations and hydrodynamic stress on cells, which can lead to changes in their morphology, metabolism and viability. However, typical dimorphic forms of the yeast were observed in the bioreactor, and cell viability was monitored without any detectable decrease with increase in the agitation (from 300 to $600 \mathrm{rpm}$ ). Thus, it is quite safe to state that at the overall operating conditions used in this work, there was no influence of $k_{\mathrm{L}} a$ on the aroma production above the minimal value of $70 \mathrm{~h}^{-1}$. In fact, the differences of aroma maximal production attained at high $k_{\mathrm{L}} a$ values are not statistically significant due to experimental error $(t$-test, $P>0.1)$. Moreover, the use of intermediate agitation rates, in contrast to higher rates, has the advantage of limiting the energetic costs of the process. 


\section{Conclusions}

An empirical correlation to predict $k_{\mathrm{L}} a$ values as a function of operating conditions (agitation and aeration rates) and of oil and surfactant fractions in a biphasic medium was established, and the effects of oil and surfactant discriminated.

The presence of oil or surfactant, in the medium, increases the overall $k_{\mathrm{L}} a$ value of the system, but the effect of oil, which is the biotransformation substrate, is opposite when the medium contains surfactant.

$k_{\mathrm{L}} a$ affects the production of $\gamma$-decalactone: a maximal aroma compound production $\left(141 \pm 21 \mathrm{mg} \mathrm{L}^{-1}\right)$ was achieved for a $k_{\mathrm{L}} a$ of $70 \mathrm{~h}^{-1}$, obtained at agitation and aeration rates of $400 \mathrm{rpm}$ and $0.6 \mathrm{vvm}$, respectively.

This work showed that $k_{\mathrm{L}} a$ is an important factor to $\gamma$ decalactone production. Thus, the correlation for $k_{\mathrm{L}} a$ prediction, herein proposed, could be very useful for further work on the development of strategies for the optimisation and scale-up of this process. Future work will be focused in the validation of the $k_{\mathrm{L}} a$ correlation at higher amounts of MR added to the medium. The impact of the use of oil as substrate and oxygen carrier on the bioprocess will be analysed, as well as the possibility of reducing/eliminating the need of surfactant addition.

\section{References}

[1] M.S. Puthli, V.K. Rathod, A.B. Pandit, Gas-liquid mass transfer studies with triple impeller system on a laboratory scale bioreactor, Biochem. Eng. J. 23 (2005) 25-30.

[2] A.H.G. Cents, D.W.F. Brilman, G.F. Versteeg, Gas absorption in an agitated gas-liquid-liquid system, Chem. Eng. Sci. 56 (2001) 1075-1083.

[3] T.R. Das, A. Bandopadhyay, R. Parthasarathy, R. Kumar, Gas-liquid interfacial area in stirred vessels: the effect of an immiscible liquid phase, Chem. Eng. Sci. 40 (2) (1985) 209-214.

[4] I.T.M. Hassan, C.W. Robinson, Oxygen transfer in mechanically agitated systems containing dispersed hydrocarbon, Biotechnol. Bioeng. 19 (1977) 661-682.

[5] L.-K. Ju, J.F. Lee, W.B. Armiger, Enhancing oxygen transfer in bioreactors by perfluorocarbon emulsions, Biotechnol. Prog. 7 (1991) 323-329.

[6] A. Leckal, R.V. Chaudhari, A.M. Wilhelm, H. Delmas, Gas-liquid mass transfer in gas-liquid-liquid dispersions, Chem. Eng. Sci. 52 (21-22) (1997) 4069-4077.

[7] V. Linek, P. Benes, A study of the mechanism of gas absorption into oil-water emulsions, Chem. Eng. Sci. 31 (11) (1976) 1037-1046.

[8] J.D. MacMillan, D.I.C. Wang, Mechanisms of oxygen transfer enhancement during submerged cultivation in perfluorochemical-in-water dispersions, Ann. N. Y. Acad. Sci. 589 (1990) 283-300.

[9] M.R. Mehrnia, J. Towfighi, B. Bonakdarpour, M.M. Akbarnejad, Gas holdup and oxygen transfer in a draft-tube airlift bioreactor with petroleumbased liquids, Biochem. Eng. J. 22 (2005) 105-110.

[10] V.D. Mehta, M.M. Sharma, Mass transfer in mechanically agitated gas-liquid contactors, Chem. Eng. Sci. 26 (1971) 461-479.

[11] J.L. Rols, J.S. Condoret, C. Fonade, G. Goma, Mechanism of enhanced oxygen transfer in fermentation using emulsified oxygen-vectors, Biotechnol. Bioeng. 35 (1990) 427-435.
[12] M.M. Sharma, R.A. Mashelkar, Absorption with reaction in bubble columns, Inst. Chem. Eng. Symp. Ser. 28 (1968) 10-21.

[13] A.B. Van der Meer, A.A.C.M. Beenackers, R. Burghard, N.H. Mulder, J.J. Fok, Gas/liquid mass transfer in a four-phase stirred fermentor: effects of organic phase hold-up and surfactant concentration, Chem. Eng. Sci. 47 (9-11) (1992) 2369-2374.

[14] F. Yoshida, T. Yamane, Y. Miyamoto, Oxygen absorption into oil-in-water emulsions. A study on hydrocarbon fermentors., Ind. Eng. Chem. Des. Dev. 9 (4) (1970) 570-577.

[15] D.R. Nielsen, A.J. Daugulis, P.J. McLellan, A novel method of simulating oxygen mass transfer in two-phase portioning bioreactors, Biotechnol. Bioeng. 83 (6) (2003) 735-742.

[16] G. Barth, C. Gaillardin, Physiology and genetics of the dimorphic fungus Yarrowia lipolytica, FEMS Microbiol. Rev. 19 (1997) 219-237.

[17] P. Fickers, F. Fudalej, J.-M. Nicaud, J. Destain, P. Thonart, Selection of new over-producing derivatives for the improvement of extracellular lipase production by the non-conventional yeast Yarrowia lipolytica, J. Biotechnol. 115 (2005) 379-386.

[18] Y. Waché, Y. Pagot, J.-M. Nicaud, J.-M. Belin, Acyl-CoA oxidase, a key step for lactone production by Yarrowia lipolytica, J. Mol. Catal. B Enzymat. 5 (1998) 165-169.

[19] M. Aguedo, Biotransformation de lipides en arômes par Yarrowia lipolytica: interactions avec le substrat, excrétion et toxicité des métabolites produits. PhD Thesis, Université de Bourgogne, Dijon, France, 2002.

[20] A. Tribe, C.L. Briens, A. Margaritis, Determination of the volumetric mass transfer coefficient $\left(k_{\mathrm{L}} a\right)$ using the dynamic "gas out-gas in" method: analysis of errors caused by dissolved oxygen probes, Biotechnol. Bioeng. 46 (1995) 388-392.

[21] N.P. Cheremisinoff, R. Gupta, Handbook of Fluids in Motion, Ann Arbor Science, England, 1983.

[22] M. Moo-Young, H.W. Blanch, Design of biochemical reactors. Mass transfer criteria for simple and complex systems, Adv. Biochem. Eng. 19 (1981) $1-69$.

[23] E. Galindo, A.W. Pacek, A.W. Nienow, Study of drop and bubble sizes in a simulated mycelial fermentation broth of up to four phases, Biotechnol. Bioeng. 69 (2) (2000) 213-221.

[24] E. Dumont, H. Delmas, Mass transfer enhancement of gas absorption in oil-in-water systems: a review, Chem. Eng. Process. 42 (2003) 419438.

[25] K. Koide, T. Hayashi, K. Sumino, S. Iwamoto, Mass transfer from single bubbles in aqueous solutions of surfactants, Chem. Eng. Sci. 31 (1976) 963-967.

[26] Y. Kawase, J.J. Ulbrecht, The effect of surfactant on terminal velocity of and mass transfer from a fluid sphere in a non-Newtonian fluid, Can. J. Chem. Eng. 60 (1982) 87-93.

[27] J.D. Sheppard, D.G. Cooper, The effects of a biosurfactant on oxygen transfer in a cyclone column reactor, J. Chem. Technol. Biotechnol. 48 (3) (1990) 325-336.

[28] M. Wagner, H.J. Pöpel, Surface active agents and their influence on oxygen transfer, Wat. Sci. Technol. 34 (3-4) (1996) 249-256.

[29] M. Aguedo, N. Gomes, E.E. Garcia, Y. Waché, M. Mota, J.A. Teixeira, I. Belo, Decalactone production by Yarrowia lipolytica under increased $\mathrm{O}_{2}$ transfer rates, Biotechnol. Lett 27 (2005) 1617-1621.

[30] P.C. Mena, M.N. Pons, J.A. Teixeira, F.A. Rocha, Using image analysis in the study of multiphase gas absorption, Chem. Eng. Sci. 60 (2005) 5144-5150.

[31] G.F. Andrews, J.P. Fonta, E. Marrota, P. Stroeve, The effect of cells on oxygen transfer coefficients. I: Cell accumulation around bubbles, Chem. Eng. J. 29 (1980) B39-B46. 